\title{
Moving forward...
}

\section{Stephen L. Vargo ${ }^{1}$}

Published online: 18 November 2019

(C) Academy of Marketing Science 2019

I was honored and delighted to have been invited to become the next editor of AMS Review, yet, at the same time, I was pretty buried in my own, ongoing research and was not harboring any burning desire to become a journal editor. Thus, I was reluctant. However, even as a former, longstanding practitioner, who entered academic marketing relatively late in life, I had long lamented (e.g., Vargo 2007, 2018) what seemed to me to be a paucity of useful, robust theory in academic marketing. Rather, academic marketing appeared to me to be more like a patchwork of midrange and micro-foundational studies and independent research streams with little to tie them together into a meaningful theoretical narrative with generalizable, normative implications. It is a situation that I believe limits practical relevance. Advancing the theoretical foundations of marketing is the mission of AMS Review. It was because I consider this mission essential to the discipline that I accepted the position.

There have been countless calls for more theory development in marketing in recent years (e.g., Hulland 2019; MacInnis 2011; Moorman et al. 2019; Yadav 2010), although the recognition of the need for more theory can be documented back for decades (e.g., Alderson and Cox 1948; Arndt 1985). Ironically, if not paradoxically, various scholars (Clark et al. 2014) have noted that conceptual articles are often the most cited and garner an exceptionally high proportion of the major awards (e.g., Maynard/Hunt Award, AMA/Sheth Foundation Award, etc.), yet, conceptual articles continue to constitute a relatively small percentage of articles in marketing-related journals in general and, arguably, an even more miniscule proportion of articles in A-level and "elite" journals. In fact, the number of conceptual articles has been shown to be declining, this despite repeated calls from journal editors for more (Moorman et al. 2019; Yadav 2010).

Stephen L. Vargo

svargo@hawaii.edu

1 University of Hawaii at Manoa, Honolulu, HI 96822, USA
Arguably, this dearth of conceptual, theoretical articles is leading to a situation that has pointed to marketing becoming increasingly characterized as a theory-importing discipline (Clark et al. 2014; Piercy 2002). Some believe academic marketing is becoming "marginalized" (e.g., Lehmann et al. 2011: see also Hunt 2018). This theory-importing characterization was perhaps understandable when academic marketing was in its infancy, but is it reasonable that the characterization continues? Given all of the research conducted under the rubric of marketing in the last $100+$ years, is it reasonable that there is so little endogenous marketing theory (see Clark et al. 2014)? Indeed, shouldn't academic marketing be generating not only more internally useful theory for informing marketing action, but also theory that is exportable to other disciplines, both within and outside of business? A number of reasons have been suggested for this situation but perhaps the most important are increased emphasis on the primacy of methodological issues and data-driven studies, along with a commensurate de-emphasis on the importance of theory, as evidenced in the decline of marketing theory courses in marketing doctoral education (Yadav 2010).

Conceptual and empirical articles are of course not polar opposites, as they are sometimes treated. Conceptual articles require, among other things, "empirical" support from existing literature and empirical articles should be conceptually, theoretically driven. More generally, it can be argued that, even in "empirical" articles, it is the conceptual, theoretical insights that are the real contribution and essentially all that is citable. Unfortunately, it seems that theory is increasingly becoming more of an add-on justification for empirical findings (i.e., postdictively offered to support them), rather than the hypotheses-generating foundations for which the empirical findings lend support. Conceptual articles, on the other hand, force the theory to stand on its own internal logic, supported by existing theory. That is, it cannot hide behind methodological rigor and data mining.

It is not the task of AMS Review to correct all of this underemphasis on theory - perhaps ironically, much of that emphasis will have to come from the academic community insistence 
that the generation, review, and publication of empirical articles becomes more theory-driven - but it is its role to contribute. This involves more than just providing an outlet for conceptual, theoretical articles. In my view, it more generally involves fostering theory development in the academic marketing community overall.

My predecessor, Manjit Yadav, has done an outstanding job of establishing a solid foundation for AMS Review, not only in increasing the number and quality of the articles published but also in beginning a number of initiatives designed to promote conceptual, theoretical development in marketing. Of particular importance is the AMS Review Theory Forum, held annually in conjunction with the AMS Annual Conference. The forum affords the opportunity for scholars at all stages to learn from and interact with scholars recognized as leaders in conceptual writing and theory building.

Also of particular note is the AMS Review-Sheth Foundation Annual Doctoral Competition for Conceptual Articles. This competition, now in its fourth year, encourages doctoral students and first-year junior professors to develop their theory building and conceptual writing skills. Up to 12 winning submissions are invited to submit their full manuscripts to AMS Review, where they will be given special consideration for publication. The student authors of the top six submissions also receive cash prizes, which are funded by the Sheth Foundation; the students are also invited to present at a special session of the AMS Annual Conference. The doctoral student competition has been particularly successful, with a number of submissions already published and others under invited revisions.

A third initiative begun by my predecessor is the Theory + Practice section of the journal. In this section, a senior, theoretically oriented practitioner who has been considering a marketing-related issue is interviewed by an academic and then a second scholar is invited to reflect on a theoretically based research approach responsive to these concerns. The intent is to demonstrate how theory and practice can mutually inform each other.

I intend to advance all of these initiatives. For the Theory Forum, I am exploring the possibility of not only holding it at the AMS Annual Conference but also expanding it to the AMS World Marketing Congress next year in Brisbane, Australia. Likewise, I am exploring the possibility of enhancing the AMS Review-Sheth Foundation Doctoral Competition to include more ongoing, scholar-to-student mentoring following the initial competition, which should increase the number and quality of publications from this initiative. The Theory + Practice section of the journal will also be continued, hopefully with an increasing diversity of scholars and practitioners involved.

In addition to these continuing initiatives, I have begun several others. The first was to increase the diversity of the editorial review board to make it more balanced and representative. To this end, $70 \%$ of the additions to the board have been international, which should facilitate the reach of the journal, both in readership and submissions.

I have also changed the organizational structure somewhat. In the past, there has been a managing editor, typically a nonacademic, who handled the logistics and some of the proofreading tasks. However, I have asked Kaisa Koskela-Huotari of Karlstad University in Sweden, to serve as assistant editor; a role that will fall somewhere between a managing editor and an associate editor. Kaisa served as my assistant editor for the Sage Handbook on Service-Dominant Logic in which she was instrumental in bringing that 41-chapter, 70-author, 760-page edition from conception to completion. I anticipate that the working relationship we developed on that project will benefit the editorial process of AMS Review. Additionally, Bernie Jaworski of the Drucker School of Management, Claremont Graduate University, has agreed to continue as the Theory + Practice special section editor. Laurie Marshall, the managing editor for Manjit Yadav's editorship, has also agreed to continue in an ad hoc role.

We plan to make liberal use of special sections/issues to create a stronger presence of the journal in the academic community. The first of these is a special section on "Advancing Conceptual, Theoretical Articles in Marketing: Importance, Writing, and Reviewing." Essentially, it represents an extension of the Theory Forum to the journal. A significant number of leading scholars have submitted manuscripts for the special section. It is scheduled for publication in June 2020.

We have also commissioned a special section on "Informing Marketing Theory through Consumer Culture Theoretics (CCT)." The underlying idea here is that marketing theory advances from its margins, the subdisciplines and newer research streams, as much, if not more so, than from its mainstream core. However, the process is slow because these research streams tend to become siloed. This special section is a first attempt at connecting the perspectives and insights of one of those research streams, CCT, with the issues of mainstream marketing in an attempt to facilitate that process. Eric Arnould, Giana Eckhardt, and David Crockett are serving as the guest editors for this special section. Other special sections are also being formulated at this time and will be announced soon. Likely topics will be "Theories of the Market" and "Theories of Sustainability." Furthermore, we encourage the community to propose timely, theory focused topics for additional special sections and, of course, to contribute to them.

Most important, we invite the academic community to be proactive in moving this young journal forward, not so much to support the journal, per se, but to further its mission of advancing the theoretical foundations of marketing. This is a mission that many have expressed to me that they believe to be vital to the discipline. In addition to suggesting and contributing to special sections, this activity can come in a variety of important ways, such as 
1. Submitting insightful, groundbreaking conceptual manuscripts to AMS Review.

2. Encouraging students and colleagues to submit to $A M S$ Review.

3. Encouraging doctoral students to take part in the conceptual writing competition.

4. Reviewing for AMS Review, as requested, paying particular attention to positive, manuscript-improving suggestions.

5. Promoting AMS Review at conferences and forums

6. Advocating for the upgrade of AMS Review on journal rating lists.

Together we can move the mission of AMS Review forward. In doing so, we will advance what I believe is (should be) the mission of the discipline: the development of robust market and marketing theory that, in turn, has practical application. Please join us in this endeavor.

\section{References}

Alderson, W., \& Cox, R. (1948). Towards a theory in marketing. Journal of Marketing, 12 (October), 137-152.

Arndt, J. (1985). Making marketing science more scientific: Role of orientations, paradigms, metaphors and Puzzel solving. Journal of Markeitng, 49(Sum), 11-23.
Clark, T, Key, T. M., Hodis, M., Rajaratnam, D. (2014). The Intellectual Ecology of Mainstream Marketing Research: An Inquiry into the Place of Marketing in the Family of Business Disciplines (n.d.). Journal of the Academy of Marketing Science, 42(3):223-241.

Hulland, J. (2019). In through the door. Journal of the Academy of Marketing Science, 47(1), 1-3.

Hunt, S. D. (2018). Advancing marketing strategy in the marketing discipline and beyond: From promise, to neglect, to prominence, to fragment (to promise?). Journal of Markeitng Management, 34(12), 16-51.

Lehmann, D. R., McAlister, L., \& Staelin, R. (2011). Sohistication in research in marketing. Journal of Marketing, 75(4), 155-165.

MacInnis, D. J. (2011). A framework for conceptual contributions in marketing. Journal of Marketing, 75(July), 136-154.

Moorman, C., van Heerde, H. J., Page Moreau, C., \& Palmatier, R. W. (2019). Challenging the boundaries of marketing. Journal of Marketing, 83(5), 1-4. https://doi.org/10.1177/0022242919867086.

Piercy, N. (2002). Research in marketing: Teasing with trivia or risking relevance? European Journal of Marketing, 36(3), 350-363.

Vargo, S. L. (2007). On a theory of markets and marketing: From positively normative to normatively positive. Australasian Marketing Journal, 15(1), 53-60.

Vargo, S. L. (2018). Marketing relevance through market theory. Revista Brasileira de Marketing, 17(05), 730-746. https://doi.org/10.5585/ bjm.v17i5.4177.

Yadav, M. S. (2010). The decline of conceptual Artiles and implications for knowledge development. Journal of Markeitng, 74(1), 1-19.

Publisher's note Springer Nature remains neutral with regard to jurisdictional claims in published maps and institutional affiliations. 